\title{
Farklı Orana Sahip PET Atıklarının Çimento Harçlarının Mekanik ve Dayanıklılık Özelliklerine Etkisi
}

\author{
Arın Yilmaz ${ }^{1 *}$ \\ 1* Balıkesir Üniversitesi, Mühendislik Fakültesi, İnşaat Mühendisliği Bölümü, Balıkesir, Türkiye (ORCID: 0000-0002-5150-5936), ayilmaz@ balikesir.edu.tr
}

(1st International Conference on Applied Engineering and Natural Sciences ICAENS 2021, November 1-3, 2021)

(DOI: 10.31590/ejosat.1004191)

\begin{abstract}
ATIF/REFERENCE: Yılmaz, A. (2021). Farklı Orana Sahip PET Atıklarının Çimento Harçlarının Mekanik ve Dayanıklılık Özelliklerine Etkisi. Avrupa ve Bilim Teknoloji Dergisi, (28), 432-436.

Öz

Plastik atıklar artan nüfusla birlikte büyük bir sorun oluşturmaktadır. Bu tür atıkların depolanması ve yok edilmesi için çalışmalar devam etmektedir. Birçok sektörde plastik atıkların geri dönüşümü ile tekrar kullanılabilir hale geldiğini biliyoruz. İnşaat sektöründe özellikle PET atıklarının hafif yapı malzemeleri üretiminde agrega olarak kullanıldığını görmekteyiz. Ayrıca malzemede oluşabilecek kılcal çatlakların önlenmesi içinde lif görevi gören PET atıklarının kullanılmaktadır. Bu çalışmada, pet atıkları içeren çimento harçlarının mekanik özellikleri deneysel olarak araştırılmıştır. Pet atıkları öncelikli olarak boyuna donatı olarak kullanılmıştır. Daha sonra aynı orandaki atık 3 farklı boyutta kesilerek sistem içine dahil edilmiştir. İki farklı durumunda kullanımı arasındaki farklar ortaya çıkarılmıştır. Pet boyutlarının küçülmesiyle birlikte basınç dayanımına etkisi artmıştır. Eğilmede çekme dayanımı yüzey alanı geniş olan PET atıklarında daha yüksek elde edilmiştir.
\end{abstract}

Anahtar Kelimeler: Pet atıkları, basınç dayanımı, eğilmede çekme dayanımı, donma çözülme direnci.

\section{Effect of PET Waste Having Different Ratio on Mechanical and Durability Properties of Cement Mortars}

\begin{abstract}
Plastic waste is a big problem with the increasing population. Efforts are underway to store and dispose of such wastes. We know that in many sectors, plastic waste becomes reusable by recycling. In the construction sector, we see that PET wastes are used as aggregate in the production of light building materials. In addition, PET wastes, which act as fibers, are used to prevent capillary cracks that may occur in the material. In this study, the mechanical properties of cement mortars containing pet wastes were experimentally investigated. Pet wastes were primarily used as longitudinal reinforcement. Then, the same amount of waste was cut at 3 different rates and included in the system. The differences between its use in two different cases have been revealed. The effect on the compressive strength increased with the reduction of pet sizes. The flexural strength in bending was higher in PET wastes with a large surface area.
\end{abstract}

Keywords: PET waste, compressive strength, flexural strength, frezing-thawing resistance.

\footnotetext{
* Corresponding Author: ayilmaz@balikesir.edu.tr
} 


\section{Giriş}

Günümüzde, uçucu kül, yüksek fırın cürufu, atık plastikler gibi endüstriyel atıkların beton üretiminde agrega olarak kullanımına yönelik ilgi giderek artmaktadır. $\mathrm{Bu}$ malzemelerin kullanımı hem çevre kirliliğini azaltmakta hem de yetersiz agrega kaynaklarına sahip bölgeler için yeni kaynak teşkil etmektedir. Ayrıca bu tür atıkların beton üretiminde agrega olarak kullanımı maliyeti de düşürmektedir. Plastik atıkların hafif olması, kimyasal etkilere karşı dirençli olması, kolay elde edilmesi gibi etkenlerden dolayı beton üretiminde olduğu gibi birçok sektörde de kullanılmaktadır. Literatüre bakıldığında beton üretiminde plastiklerin kullanımı genellikle agrega yerine kullanılması şeklinde olmuştur (Benazzouk ve ark., 2003; Akçaözoğlu ve ark., 2010).

Polietilen tereftalat genellikle PET olarak kisaltılan polyester ailesine ait termoplastik polimer reçinesi olarak bilinmektedir. S1vı olarak tükettiğimiz plastik kapların hepsi bu malzemeden üretilmekte ve kısaca PET ismini almaktadır. PET atıklarının depolanması ve yok edilmesi Dünyada büyük sorunları beraberinde getirmektedir. PET atıklarının geri dönüşümü, bunların kompozit bir yapı malzemesinin bileşeni olarak kullanılmasıyla da mümkün olabilmektedir. Betonun çekme dayanımını iyileştirmek için fiber takviyesi olarak PET fiberleri kullanılmıştır (Kim ve ark., 2010). Bilindiği üzere beton, basınç yükü altında güçlü, çekme yükü altında ise zayıftır. Yapılan bir çalışmada, PET atıklarının rötre çatlaklarını kontrol etmede etkili rol oynadığı çekme dayanımını artırmadığı ifade edilmiştir (Kim ve ark., 2008). Naik ve ark., (1996) çalışmalarında basınç dayanımını artırmak için kimyasal olarak işlenmiş yüksek oranda PET atığını betonda dolgu maddesi olarak kullanmışlardır. Bu çalışmanın sonucunda betonun basınç dayanımının kimyasal işlem görmüş atıklardan olumlu olarak etkilendiğini belirtmişlerdir. Başka bir çalışmada, Sivaraja ve ark., (2010) naylon, plastik ve lastik gibi atıkların beton dayanımı üzerindeki etkisini araştırmıştır. Deney sonuçları \% 0.5-1 oranına sahip atıkların mekanik mukavemeti arttırdığını ortaya koymuştur. Diğer bir çalışma Rebeiz ve ark., (1996) Petten oluşan doymamış polyester reçine ile üretilen çelik takviyeli betonun eğilme davranışını araştırmıştır. Çalışmalarında, kirişlerin eğilme mukavemetinde artış olduğunu ifade etmişlerdir.

Plastik atıkları, bazı araştırmacılar tarafından hafif yapı elemanlarının üretiminde agrega olarak kullanılmıştır. Plastik atıkların mekanik olarak ayrılması ve işlenmesi ile üretilen plastik agrega, doğal agregalardan önemli ölçüde daha hafif malzemelerdir. Choi ve ark., (2005) tarafından yapılan bir başka çalışmada, PET atıklarının agrega olarak kullanılmasının betonun özelliklerine olan etkileri araştırılmış ve plastiğin betonun ağırlığını yaklaşık \%2-6 oranında azalttığı tespit edilmiştir. Aynı zamanda normal betonun basınç dayanımı \%33'e kadar azaldığını elde etmişlerdir. Batayneh M. ve ark., (2007) plastik atık içeren bir beton üzerinde bir dizi deneyler yapmıştır. Yaptıkları çalışmada yer değiştirme açısından basınç dayanımı dikkate alındığında, kontrol numunesinin basınç dayanımının $\% 5$ ve $\% 20$ oranında yer değiştirilmiş atıklara göre sırasıyla $\% 23$ ve $\% 72$ oranında azaldığını ifade etmişlerdir. Beton karışımında ince agrega yerine PET atığının \%2 ile \%100 ikame miktarı olarak kullanımını inceleyen bir çalışmada, PET agregaları ile yoğunluk ve basınç dayanımı arasında, pozitif bir korelasyon elde edilmiştir. Parçalanmış PET parçacıklarının çimento harcında ince agrega olarak kullanılabileceği sonucuna varılmıştır (Marzouk ve ark., 2007). Yukarıda ifade edilen çalışmalar sonucunda, öğütülmüş PET atıklarının lif etkisi göstererek düşük maliyetli bir malzeme sunma konusunda işlevsel hale gelmişlerdir. Ghaly ve Gills (2004) tarafindan plastik atıkların iri agregalar yerine kullanımı ile yoğunluk, suçimento oranı ve plastik içeriği üzerindeki etkileri gözlenmiştir. Çalışmanın sonucunda plastik atıkların yoğunluğu azalttığı ve özellikle sert hava koşulları için üstün veya ekstra deformasyon nitelikleri sağladığını göstermiştir. Zainab Z. İsmail ve ark., (2008) fabriform şekilli atık plastikleri beton karışımında \%20'ye kadar ince agrega yerine kullanmış ve mikro çatlakların yayılmasının atık plastikler tarafından durdurulduğu sonucuna varılmışlardır.

$\mathrm{Bu}$ çalışmada, öncelikli olarak boyuna donatı olarak kullanılan 2 faklı genişliğe sahip pet atığının çimento harcının mekanik ve dayanıklılık özelliklerine etkisi incelenmiştir. Daha sonra, 3 faklı boyutta kesilerek (lif oranı sabit kalmak şartı ile) dağınık bir şekilde matriks içinde dağılımının etkisi incelenmiştir. Pet atıklarının boyuna donatı gibi kullanımı ile aynı orandaki pet atıklarının lif şeklinde dağılımları karşılaştırılmıştır.

\section{Materiyal ve Yöntem}

Deneysel çalışmada L/D oranı farklı 8 tip kesilmiş pet atıkları kullanılmıştır. Portland çimentosu Balıkesir Limak Çimento fabrikasından CEM-I (PÇ 42.5 R) olarak temin edilmiştir. Pet atıkları ilk grupta boyuna donatı görevini görecek şekilde $4 * 4 * 16 \mathrm{~cm}$ lik standard kalıpların içine Şekil 1 de gösterildiği gibi sabitlenmiştir. 2. Grup olarak farklı L/D oranı şeklinde kesilip $4 * 4 * 4 \mathrm{~cm}$ boyutlarında harç numunesi üretimi sırasında aynı oranı teşkil edecek şekilde sisteme kesilmiş olarak dahil edilmiştir. Karışımdaki pet atıklarının boyutları Tablo 1'de verilmiştir. Portland çimentosunun kimyasal analizi ise Balıkesir Limak Çimento Fabrikasının laboratuarlarında yapılmıştır. Kimyasal analiz için X-1şını kırılma yöntemi kullanılmış ve kimyasal analiz sonuçları Tablo 2'de belirtilmiştir.

Harç numuneleri, TS EN 196-1'de (2002) belirtilen oranlarda karışım oranlarına uygun şekilde üretilmiştir. Hazırlanan çimento harç, $4 \times 4 \times 16 \mathrm{~cm}$ boyutlarındaki standard prizmatik kalıplara ve $4 * 4 * 4 \mathrm{~cm}$ boyutlarındaki küp kalıplara dökülmüştür. 1 gün süreyle kalıpta bekletilen numuneler $\% 95$ nem ve $20^{\circ} \mathrm{C}$ sıcaklığa sahip kür odasında bakımları yapılmıştır. Harç numuneleri kalıplardan çıkarıldıktan sonra $20 \pm 2{ }^{\circ} \mathrm{C}$ sabit sıcaklığa sahip kür havuzlarına konulmuştur. 2., 7., 28. günlerde eğilmede çekme ve basınç deneyleri uygulanmıştır.

28 gün sonunda numuneler üzerinde tahribatsız deney yöntemlerinden biri olan ultra ses geçiş deneyleri yapılmış ve gerekli ölçümler alınmıştır. Ayrıca donma çözülme deneyleri yapılmıştır.

Donma-çözülme deneyleri için 28 gün bakımları yapılan numuneler, $-20^{\circ} \mathrm{C}$ 'de donma çözülme cihazında 4 saat bekletildikten sonra 4 saat $20^{\circ} \mathrm{C}$ sıcaklığında aynı cihaz içinde çözülmeleri sağlanmıştır. $\mathrm{Bu}$ döngü $25 \mathrm{kez}$ tekrarlanmış ve donma-çözülme döngüsü sonunda numuneler basınç dayanımına tabi tutulmuştur. Aynı süreç içinde bakımına devam edilen kontrol numuneleri üzerinde de basınç deneyleri uygulanmış ve dayanım kayıpları (\%) belirlenmiştir. 

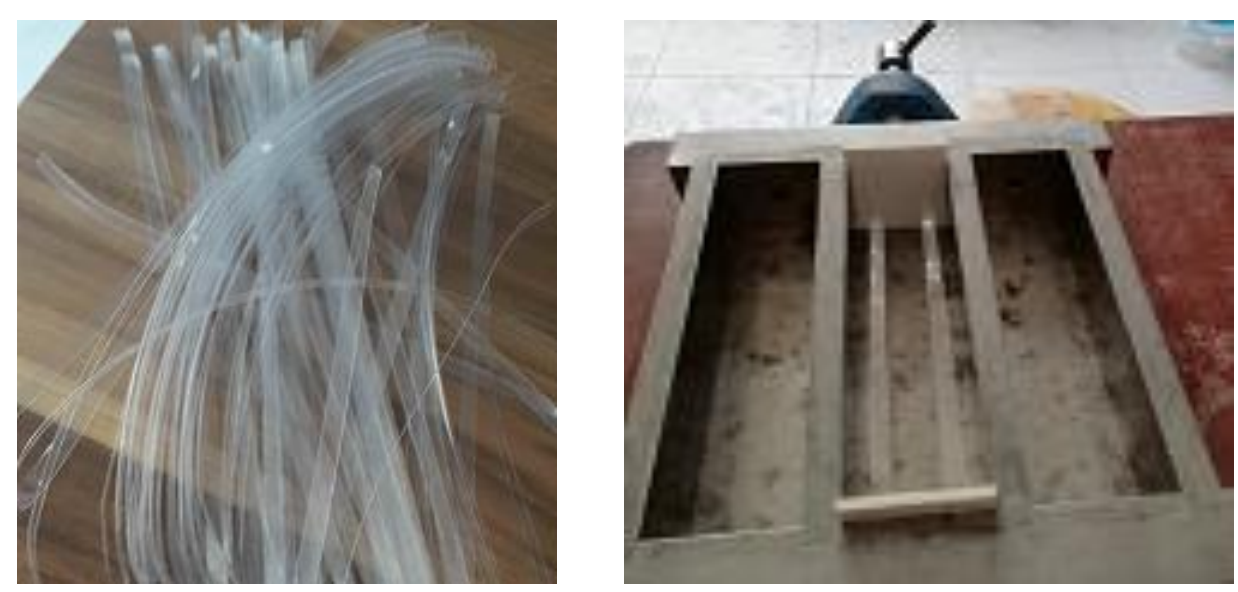

Şekil 1. Hazırlanan Pet Atıkları ve Kalıp İ̧̧inde Yerleşimi

Tablo 1. Çalışmada Kullanilan Pet Boyutları

\begin{tabular}{|c|c|c|c|}
\hline Numuneler & Uzunluk (L,cm) & Genişlik (D, cm) & Açıklama \\
\hline $\mathrm{P} 1$ & 1 & 0,25 & \multirow{6}{*}{$\begin{array}{l}\text { Farklı boyutlarda kesilmiş } \\
\text { dağınık yayılmış pet atıkları }\end{array}$} \\
\hline P2 & 1 & 0,5 & \\
\hline P3 & 1,5 & 0,25 & \\
\hline $\mathrm{P} 4$ & 1,5 & 0,5 & \\
\hline $\mathrm{P} 5$ & 2,5 & 0,25 & \\
\hline P6 & 2,5 & 0,5 & \\
\hline P7 & 15,4 & 0,25 & \multirow{4}{*}{$\begin{array}{l}\text { Kesilmeden boyuna } \\
\text { yerleştirilen pet atıkları }\end{array}$} \\
\hline P8 & 15,4 & 0,5 & \\
\hline P9 & 15,4 & 0,25 & \\
\hline P10 & 15,4 & 0,5 & \\
\hline
\end{tabular}

Tablo 2. Portland Çimentosunun Kimyasal Bileşeni

\begin{tabular}{|c|c|c|c|c|c|c|c|c|c|c|}
\hline$\%$ & $\mathrm{SiO}_{2}$ & $\mathrm{CaO}$ & $\mathrm{Al}_{2} \mathrm{O}_{3}$ & $\mathrm{Fe}_{2} \mathrm{O}_{3}$ & $\mathrm{MgO}$ & $\mathrm{SO}_{3}$ & $\mathrm{~K}_{2} \mathrm{O}$ & $\mathrm{Na}_{2} \mathrm{O}$ & K.Kayb1 & S. $\mathrm{CaO}$ \\
\hline $\mathrm{PC}$ & 21,26 & 62,48 & 6,04 & 3,55 & 1,35 & 2,45 & 0,88 & 0,16 & 1,9 & 1,51 \\
\hline
\end{tabular}

\section{Bulgular}

Öncelikle pet atıklarını boyuna donatı olarak kullanımının etkisi incelenmiştir. Şekil 2'de prizmatik numunelerin 28 günlük eğilmede çekme dayanımı grafikleri oluşturulmuştur. Genişlikleri $(\mathrm{D}=0,25 \mathrm{~cm}$ ve $\mathrm{D}=0,50 \mathrm{~cm})$ farklı 2 adet pet donatısı kalıplar içerisine 2 faklı yönde yerleştirilmiştir. Kirişler üzerine etkiyen yük petlerin üzerine enine ve dikine gelecek şekilde uygulanmıştır (Tablo 1). Şekil 2'de görüldüğü üzere petlere enine (P9 ve P10) olarak uygulanan kuvvet sonucunda hesaplanan eğilmede çekme dayanımları doğal olarak yüksek çıkmıştır. Her iki farklı yükle durumu incelendiğinde $0,25 \mathrm{~cm}$ enine sahip numunelerin eğilmede çekme dayanımı yüksek çıkmıştır. En yüksek değer olan 4,01 $\mathrm{MPa}$ değeri P9 numunesinden elde edilmiştir. Eğilmede çekme deneyi sonucunda ikiye ayrılan numuneler üzerine basınç dayanımı uygulanmıştır. Elde edilen basınç dayanımı sonuçları Şekil 3 'de gösterilmiştir. Şekil 3 incelendiğinde eğilmede çekme dayanımı ile benzer sonuçların ortaya çıktığı görülmektedir.

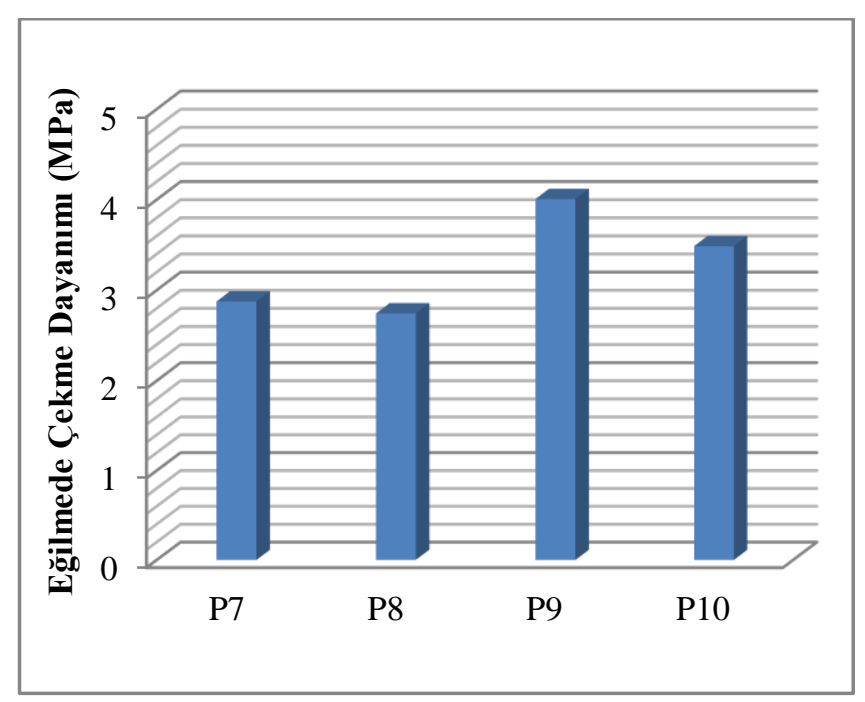

Şekil 2. Boyuna Yerleştirilen Pet Atıklarının 28 günlük Eğilmede Çekme Dayanımına Etkisi 


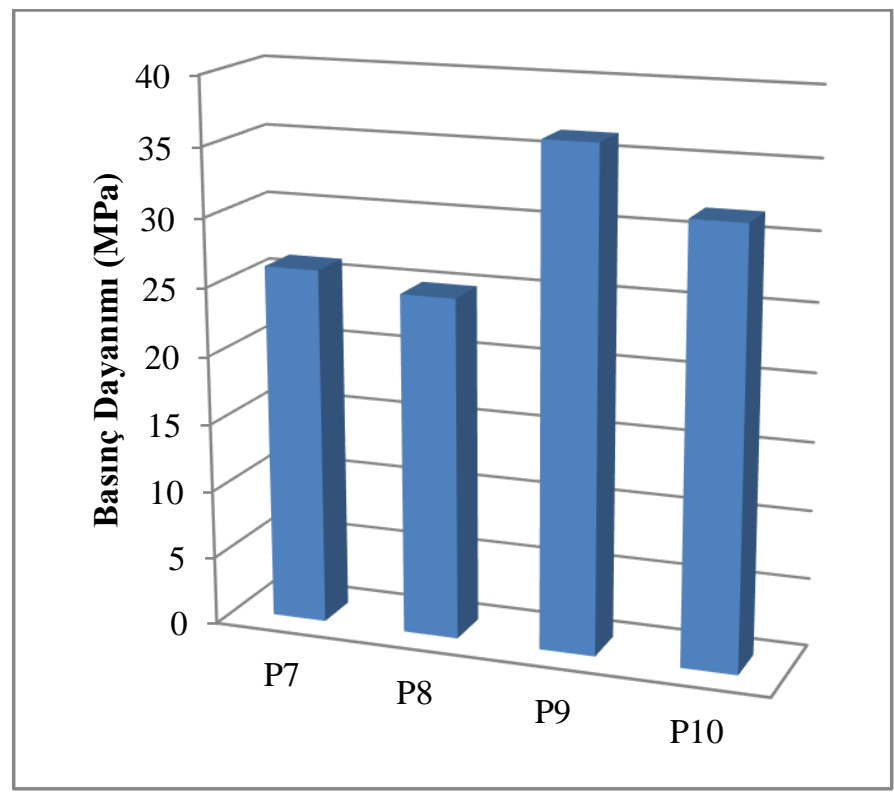

Şekil 3. Boyuna Yerleştirilen Pet Atıklarının 28 günlük Basınç Dayanımına Etkisi

Aynı orandaki petlerin farklı boyutlarda kesilerek sisteme dahil edilmesiyle $4 * 4 * 4 \mathrm{~cm}$ lik harç numuneleri elde edilmiştir. Harç numuneleri üzerinde 2, 7 ve 28 günlük basınç dayanımı deneyleri yapılmış ve deney sonuçları Şekil 4'de gösterilmiştir. $0,25 \mathrm{~cm}$ genişliğine sahip pet atıklarının 28 günlük dayanımları uzunluk arttıkça artmaktadır. $\mathrm{D}=0,5$ cm'lik numunelerde ise tam tersi 28 günlük dayanım değerleri azalmıştır. Bunun nedeni ince lif etkisinin sistem içinde dağılımından kaynaklı basınç dayanıma etkisini daha fazla olmasından kaynaklandığı söylenebilir.

En yüksek 28 günlük basınç dayanımı değeri $\mathrm{P} 2(\mathrm{~L}=1 \mathrm{~cm}$ ve $\mathrm{D}=0,5 \mathrm{~cm}$ ) numunesinden elde edilmiş olup basınç dayanımı 38,4 MPa'dır. Numunelerin L/D oranlarına bakılarak sonuçların yorumlanması durumunda en düşük orana $(\mathrm{L} / \mathrm{D}=2)$ sahip $\mathrm{P} 2$ numunesinin basınç dayanımının yüksek çıktığı ifade edilebilir. Sisteme katılan kesilmiş pet atıklarının agrega görevi gördüğü düşünüldüğünde, şekil olarak pet boyutlarının birbirine yakın olduğu durumda basınç dayanımının yüksek çıkması beklenen bir sonuçtur.

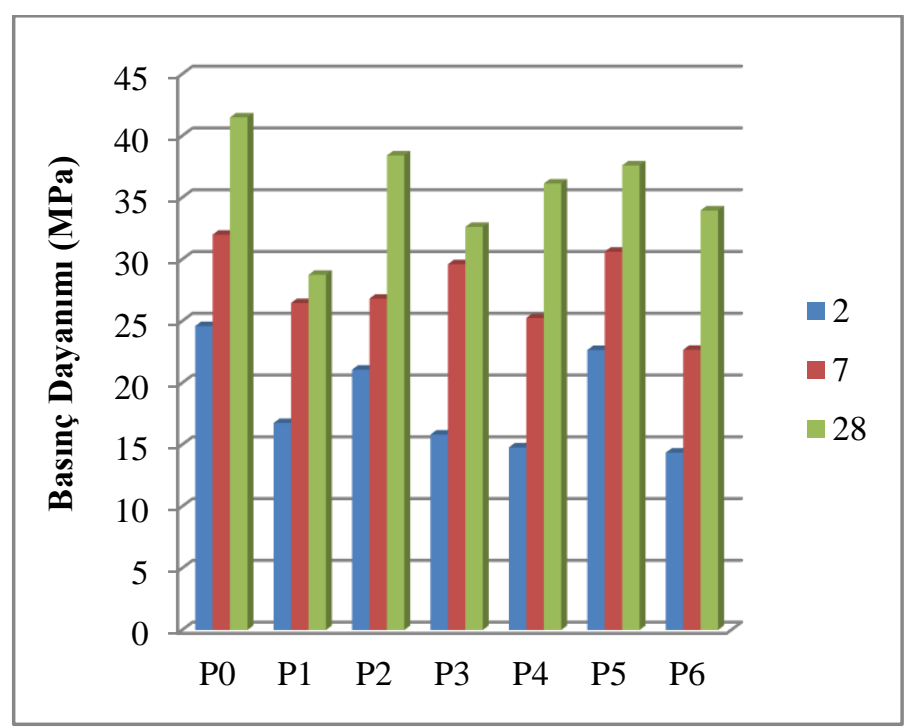

Şekil 4. Farklı Boyutlarda Kesilmiş Dă̆ınık Yayılmış Pet Atıklarının 28 günlük Basınç Dayanımına Etkisi
Çalışmada 28 günlük numuneler üzerinde ultrases geçiş hızı ölçüm deneyleri yapılmıştır. Ultra ses hızları ve 28 günlük basınç dayanımları arasındaki ilişki Şekil 5 'de doğrusal bir grafik çizilerek oluşturulmuştur. Şekil 5 incelendiğinde ultrases geçiş hızı artıkça pet karışımlı numunelerin basınç dayanımlarının azaldığı görülmektedir $\left(\mathrm{R}^{2}=0,86\right)$. Bu durumun nedeni şöyle açıklanabilir; sistem içindeki kesilmiş petlerin içyapıdaki boşluk oranını artırmayarak taneler arasındaki bağı daha kuvvetli hale getirmesinden kaynaklandığı söylenebilir.

25 döngü sonucunda donma-çözülme etkisindeki basınç dayanımı değişimi Şekil 6'da verilmiştir. Çimento harcı içerisindeki pet atıklarının boyutlarının artması donmaçözülme etkisine karşı dayanıklılığını azalttığını söyleyebiliriz.

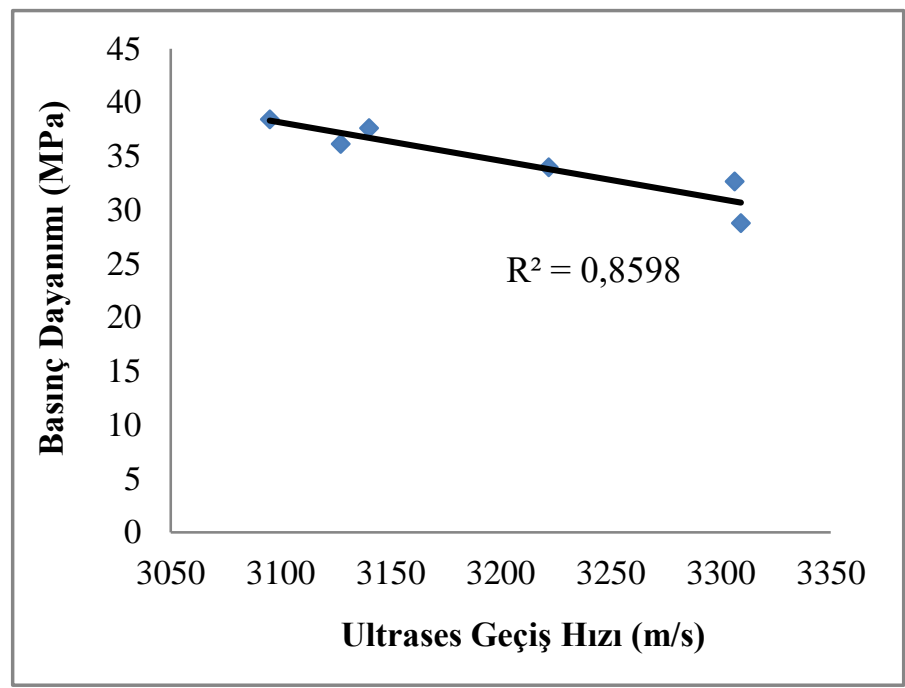

Şekil 5. Pet Atıkları İçeren Numunelerin Ultrases -Basınç Dayanımı İlişkisi

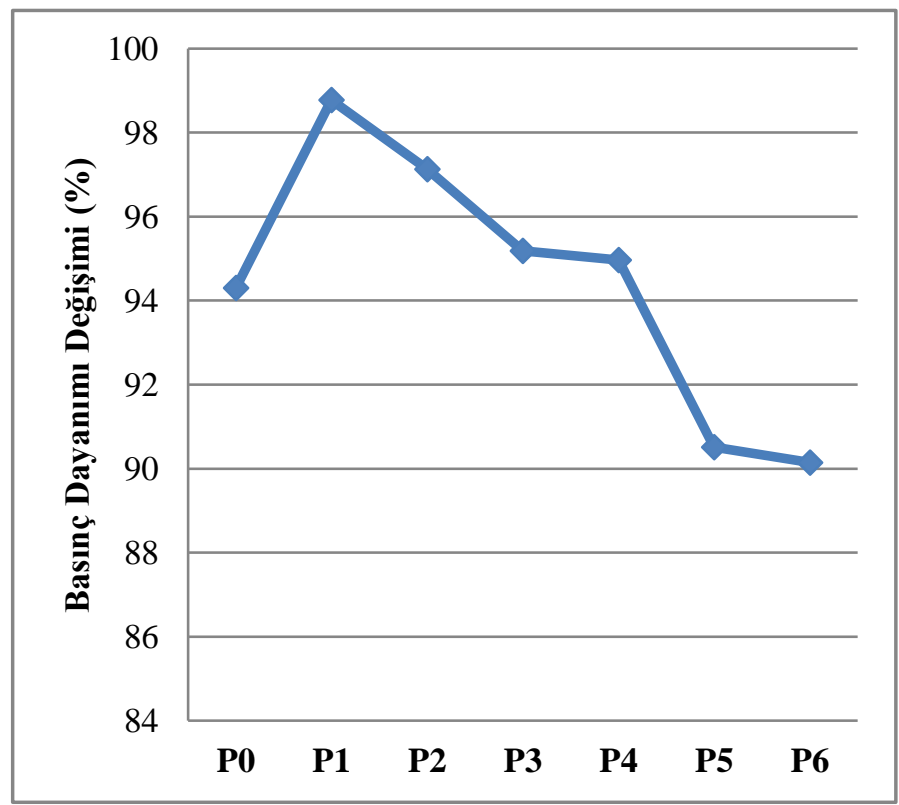

Şekil 6. Donma Çözülme Etkisinde Basınç Dayanımındaki Değişim (\%) 


\section{Sonuçlar}

Çalışmada aşağıdaki sonuçlara varmak mümkün olacaktır;

1) Pet atıklarının boyuna donatı olarak kullanıldığ durumunda, genişliği $\mathrm{D}=0,25 \mathrm{~cm}$ olan enine gelecek şekilde yüklenen numunenin eğilmede çekme dayanımı ve basınç dayanımı en yüksek değer olarak elde edilmiştir (P9).

2) Aynı orandaki petlerin farklı boyutlarda kesilerek sisteme dahil edilmesi durumunda, en yüksek 28 günlük basınç dayanımı değeri $\mathrm{P} 2(\mathrm{~L}=1 \mathrm{~cm}$ ve $\mathrm{D}=0,5 \mathrm{~cm})$ numunesinden elde edilmiştir.

3) Ultrases geçiş hızı artıkça pet karışımlı numunelerin basınç dayanımlarının azaldığı görülmektedir $\left(\mathrm{R}^{2}=0,86\right)$.

4) Pet atıklarının donma-çözülme dayanıklılı̆ğna etkisinin pet boyutlarının artması ile azaldığını söyleyebiliriz.

Çalışmanın bir sonraki adımı için, farklı dayanıklılık özelliklerinin de incelenmesi uygun olacaktır. Ayrıca gerilme şekil değiştirme davranışının elde edilmesi sonucunda mekanik davranış hakkında daha farklı bilgilere de ulaşılabilir.

\section{Kaynakça}

Akçaözoğlu S., Atis C.D., Akçaözoğlu K. (2010). An investigation on the use of shredded waste PET bottles as aggregate in lightweight concrete. Waste Management, 30(2), 285-290.

Batayneh M., Marie I., Asi I. ( 2007). Use of Selected Waste Material in Concrete Mixes. Waste Management, 27(12),1870- 1876.

Benazzouk A., Mezreb K., Doyen G., Goullieux A., Queneudec M. (2003). Effect of rubber aggregates on the physico-mechanical behaviour of cement-rubber composites-influence of the alveolar texture of rubber aggregates. Cem.Concr. Compos. 25(7), 711-720.

Choi Y.W., Moon D.J., Chung J.S., Cho S.K. (2005). Effects of waste PET bottles aggregate on the properties of concrete. Cem Concr Res 35, 776-781.

Ghaly A., Gill M. (2004). Compression and Deformation Performance of Concrete Containing Postconsumer Plastics. ASCE, J. Mater. Civ. Eng., 16(4), 289-296.

Kim J.H.J., Park C.G., Lee S.W., Lee S.W., Won J.P. (2008). Effects of the geometry of recycled PET fiber reinforcement on shrinkage cracking of cement-based composites. Compos. Part B Eng. 39, 441-450.

Kim S.B., Yi N.H., Kim H.Y., Kim J.H.J., Y Song.C. ( 2010). Material and structural performance evaluation of recycled PET fiber reinforced concrete. Cement Concrete Composite, 32, 232-240.

Marzouk O.Y., Dheilly R.M., Queneudec M. (2007). Valorization of Post Consumer Waste Plastic in Cementitious Concrete Composites. Waste Management, 27 (2), 310-318.

Naik T.R., Singh S.S., Huber C.O., Brodersen B.S. (1996). Use of Post-Consumer Plastics in Cement Based Composites. Cement and Concrete Research, 26, (10), 1489-1492.
Rebeiz K.S. D. Fowler W. (1996). Flexural Strength of Reinforced Polymer Concrete Made with Recycled Plastic Waste. ACI Structural Journal, 93,(5), $524-530$.

Sivaraja M., Kandasamy S., Thirumurugan A. (2010). Mechanical Strength of Fibrous Concrete with Waste Rural Materials. Journal of Engineering and Applied Science, $69,308-312$.

TS EN 196-1 (2002) Methods of testing cement-part: 1 Determination of strength. Ankara, Turkey: Turkish Standard Institute.

Zainab Ismail Z., Al - Hashmi Enas A. (2008). Use of Waste Plastic in Concrete Mixture as Aggregate Replacement. Waste Management, 28 (11), 2041 - 2047. 